\title{
Digital Game Based Learning Tebak Nama Buah dan Sayuran Dalam Bahasa Inggris Dengan Model Addie
}

\begin{tabular}{|c|c|c|}
\hline \multicolumn{3}{|c|}{ Indarti $^{1}$, Dewi Laraswati ${ }^{2}$} \\
\hline \multicolumn{3}{|c|}{$\begin{array}{l}\text { 1,2Universitas Bina Sarana Informatika } \\
{ }^{1} \text { e-mail: indarti.ini @ bsi.ac.id } \\
{ }^{2} \text { e-mail: dewi.dwl @ bsi.ac.id }\end{array}$} \\
\hline Diterima & Direvisi & Disetujui \\
\hline $22-10-2020$ & $18-01-2021$ & $23-01-2021$ \\
\hline
\end{tabular}

\begin{abstract}
Abstrak - Pembelajaran pada masa pademi ini menuntut peneliti lebih kreativitas di dalam membuat metode pembelajaran supaya siwa yang mempelajarinya tidak merasa bosan atau menjadi pasif terapi antusias didalam belajar lebih tinggi. Digital game based learning (DGBL) model belajar yang berbasis game digital supaya anakanak lebih interaktif. Metode pengembangan pembelajaran berbasis game atau Game Based Learning dapat menggunakan ADDIE atau Analyzing, Designing, Developing, Implementing and Evaluating.
\end{abstract}

Kata Kunci: Game Edukasi, Model Addie, nama buah dan sayuran.

Abstract - Learning in the pademi craves the more creativity from in making the learning methods he continued to shiva learning it not bored or being passive therapy enthusiastic learning in higher.Digital games based learning (DGBL) model learning based digital game so that children. more interactive Method of development learning based game or games based learning can use analyzing, addie was or designing, developing, implementing and evaluating.

Keywords: Educational Game, a model addie, name fruit and vegetable

\section{PENDAHULUAN}

Pada masa pandemi ini menuntut proses pembelajaran dilakukan secara online atau pendidikan jarak jauh. Disini membuat para guru atau tenaga kependidikan harus berfikir kreatif dalam menyajikan materi pembelajaran. Salah satu yang bisa diterapkan yaitu dengan model belajar berbasis game digital atau digital game based learning (DGBL). Dimana saat ini kondisi peserta didik yang semua aktifitas mereka selalu dihimbau untuk tetap di rumah termasuk di dalamnya sekolah dari rumah atau school from home (SFH) membuat model belajar berbasis game digital sebuah pilihan proses pembelajaran dimana dengan metode ini dapat mengurangi waktu pengajaran di berbagai disiplin ilmu dan dapat menjangkau semua usia. Keefektifan Pembelajaran berbasis game digital juga membuat materi pembelajaran dapat terdokumentasi dengan baik. Penelitian sebelumnya mengatakan beberapa efek positif yang ditemukan dengan model belajar berbasis game digital yaitu dengan materi yang disampaikan berupa game maka peserta didik melakukan proses belajar pada saat mereka memainkan permainan sehingga dapat mempengaruhi pembelajaran dan keterampilan peserta didik disaat memaikan permaianan maka akan terjadi koordinasi visual antara tangan dan mata saat itu peserta didik melakukan pembelajaran konsep dan fakta secara sederhana.

Pada penelitian sebelumnya dikatakan bahwa dengan memanfaatkan Teknologi dengan baik maka dapat meningkatkan efektifitas proses belajar (Elita \& Asrori, 2019). Pada penelitian lainnya dengan digital game base learning peserta didik bisa lebih termotivasui dan mandiri dalam proses pembelajaran (Putri \& Muzakki, 2019)

Pembelajaran menggunakan digital based games membuat peserta didik mencoba dengan berbagai perilaku dan langsung dapat menerima resiko dengan berbagai tantangan yang dihadapi sehingga dapat berperilaku untuk dapat lebih berinisiatif. Dalam proses itu semua akan menghasilkan kegagalan dan keberhasilan yang nantinya akan menjadi pengalaman yang dapat diulang kembali sehingga menimbulkan proses pembelajaran bagi peserta didik (Hidayat et al., 2018).

\section{A. Digital Game Based Learning}

Menurut Coffey dalam (Khoerunnisa, 2016) Digital Game-Based-Learning merupakan metode pembelajaran yang menggabungkan konten pendidikan atau prinsip-prinsip belajar dengan game 
yang bertujuan untuk menarik siswa untuk belajar. Digital Game Base Learning menghubungkan konten pendidikan dengan komputer atau video game sehingga dapat digunakan untuk semua pelajaran dan tingkatan pendidikan. Sehingga terdapat proses interaktif antara peserta didik dengan instruksi yang harus diikuti dari game tersebut dan sekaligus menjadikan peserta didik paham akan teknologi.

Multimedia merupakan perpaduan beberapa sarana yang dapat berupa teks atau tulisan, gambar, audio, video ataupun animasi yang memberikan informasi dalam bentuk digital. Adapun contoh peralatan digital diantaranya komputer, smartphone, tablet dll.

\section{Karakteristik Game-Based Learning}

Dalam pembuatan animasi digital game base learning ada beberapa karakteristika yang harus diperhatikan diantaranya :

1. Dalam game edukasi bisa dibuat dalam bentuk dengan tingkatan level kesulitan yang berbedabeda dalam mengerjakan sebuah game.

2. Bagaimana game bisa dikemas dalam bentuk yang menarik dan menyenangkan saat dimainkan tanpa mengabaikan kompetensi yang diingikan untuk peserta didik.

3. Game yang dirancang harus bersifat interaktif

4. Game edukasi yang dibuat dapat meningkatkan kerjasama antara peserta didik dan terjadi pertukaran pendapat dan pengetahuan ketika peserta didik yang memainkan game edukasi.

5. Ketika memainkan game edukasi maka akan jika peserta didik mengalami kegagalan maka disitu akan diberikan kesempatan untuk dapat mengevaluasi kinerja mereka dan apa yang mereka pelajari dari memainkan sebuah game, misalnya kenapa mereka kalah dan bagaimana cara mengatasinya agar tak terulang lagi.

\section{Rancangan Penelitian}

Penelitian yang penulis lakukan menggunakan desain pengembangan ADDIE atau Analyzing, Designing, Developing, Implementing and Evaluating adalah salah satu model yang telah umum digunakan untuk pengembangan aplikasi multimedia salah satu contoh penggunaannya yaitu pembelajaran berbasis game atau Game Based Learning. Menurut Sugiarsana dalam (Sari \& Sakdiah, 2016) model ADDIE digunakan karena kemudahan dalam memahami tahapan pengembangan sistem.dengan model ADDIE terdiri dari lima tahapan yaitu analisa, desain, pengembangan, implementasi dan evaluasi.

1. Analisa, merupakan proses analisa kebutuhan. Pada tahapan analisa dilakukan untuk menentukan masalah dan solusi yang tepat serta menentukan kompetensi dari sasaran aplikasi yang dibuat.
2. Desain, dalam proses desain disini akan ditentukan kompetensi dan strategi pembelajaran dengan menggunakan pemetaan pikiran atau mind mapping.

3. Implementasi, implementasi dilakukan pada game tebak buah dan sayuran dalam bahasa Inggris hingga implementasi pemetaan pikiran.

4. Evaluasi, dilakukannya evaluasi game tebak buah dan sayuran dalam bahasa Inggris beserta hasil akhir pembelajaran game tebak buah dan sayuran dalam bahasa Inggris.

\section{E. Game Based Learning Tebak Nama Buah dan Sayuran.}

Game base learning ini dibuat dalam bentuk kuis dengan tujuan agar lebih mudah dipahami dan menyenangkan. . Kuisini merupakan permainan edukatif tentang menebak nama buah dan sayuran dalam bahasa inggris. Dimana kuis ini menampilkan animasi tombol, buah dan sayuran yang menarik dan di akhir menampilkan skor dari setiap user yang telah menjawab semua pertanyaan.

\section{F. Mind Mapping}

Menurut Tony Buzan, 2017 Mind Mapping adalah salah satu metode pembelajaran aktif (active learning). Mind Mapping merupakan salah satu metode pembelajaran yang sangat inovatif dan adanya kreatifitas siswa dan guru, terlebih lagi kepada para siswa yang langsung terlibat aktif dalam pembelajaran tersebut. Kreatifitas merupakan sesuatu yang paling penting untuk dimiliki oleh setiap orang karena dengan adanya jiwa kreatifitas seseorang akan terbuka peluang bagi seseorang tersebut untuk memiliki inovasi inovasi baru dan perubahany ang lebih baik lagi. Dalam membuat perubahan yang baik, maka kreativitas sangat dibutuhkan oleh guru.

Menurut Istarani (2012:60), Mind Mapping atau pemetaan pikiran merupakan cara kreatif bagi tiap pem)belajar untuk menghasilkan gagasan, mencatat apa yang dipelajari, atau merencanakan tugas baru. Pemetaan pikiran merupakan cara yang sangat baik untuk menghasilkan dan menata gagasan sebelum mula menulis.

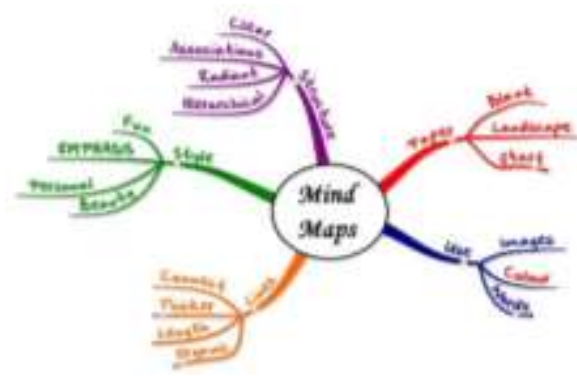

Sumber : Buzan,2007:15

Gambar 1.

Cara Membuat Mind Mapping 


\section{METODOLOGI PENELITIAN}

Langkah penelitian pada penelitian ini dilakukan sesuai dengan tahapan proses pada model ADDIE.

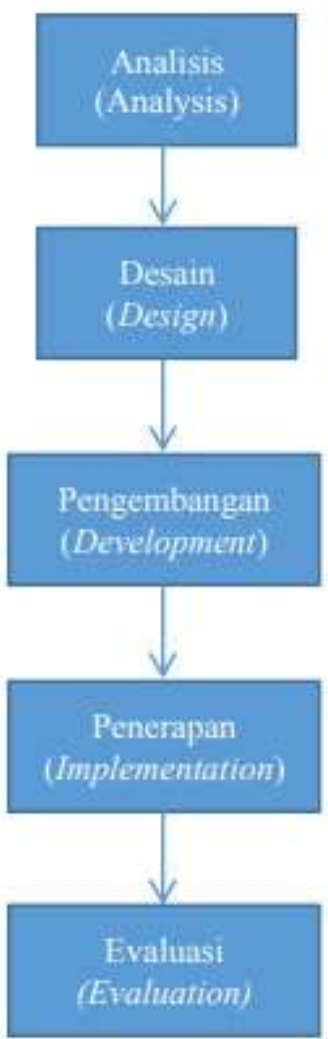

Sumber : Sugiyono dalam (Rosmiati, 2019)

Gambar 2. Langkah-langkah model pengembangan ADDIE

Tahapan proses pada model ADDIE yaitu :

a. Analisis (Analyzing), pada tahapan ini maka peneliti akan melakukan pendefinisian sistem. Pada tahapan ini dilakukan analisa kebutuan animasi edukasi yang dibuat, karakteristik peserta didik dan spesifikasi minimal perangkat lunak dan perangkat keras

b. Desain (Designing) Proses desain merupakan proses yang dilakukan sebelum pengembangan. Pada proses ini, dilakukan dengan membuat rancangan storyboard tampilan menu utama, Storyboard tampilan menu input nama, Storyboard tampilan menu kuis, Storyboard tampilan petunjuk permainan, Storyboard tampilan kategori belajar buah dan sayuran.

c. Pengembangan (Developing), pada tahapan ini selanjutnya akan dilakukan pembuatan aplikasi berdasarkan desain yang dibuat. Desain yang ada kemudian dibuat menjadi sebuah aplikasi game edukasi

d. Implementasi (Implementing), pada tahapan ini dilakukan uji coba terhadap aplikasi animasi tebak nama buah dan sayuran dalam bahasa inggris

e. Evaluasi (Evaluating) Evaluasi adalah tahapan akhir yang dilakukan dalam model ADDIE. Pada tahapan ini dilakukan untuk melihat apakah aplikasi animasi edukasi yang selesai dibuat sudah sesuai atau belum. Pada tahapan evaluasi dilakukan perbaikan aplikasi berdasarkan pengujian aplikasi di lapangan.

\section{HASIL DAN PEMBAHASAN}

Storyboard ini menggambarkan halaman menu utama dari permainan yang ditampilkan. Didalamnya terdapat tampilan-tampilan teks dan tombol yang jika di klik masuk ke halaman masingmasing.

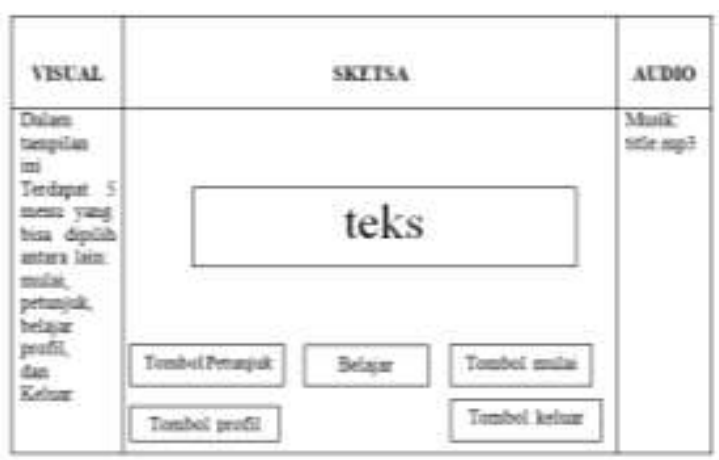

Gambar 3.

Storyboard tampilan Menu Utama

Pada gambar storyboard menu utama diatas terdapat pilihan tombol petunjuk penggunaan, tombol profil, tombol belajar, tombol mulai dan tombol keluar.

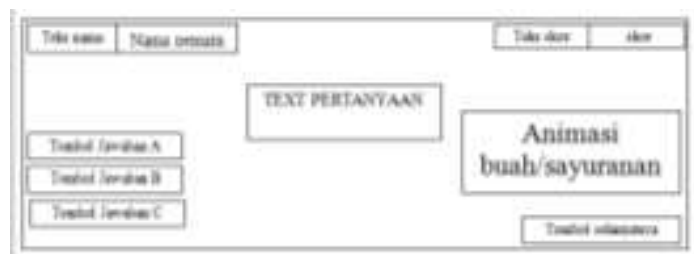

Gambar 4.

Storyboard tampilan Menu input nama

Pada tampilan story board input nama, peserta didik sebelum memulai kuis bisa memasukkan nama.

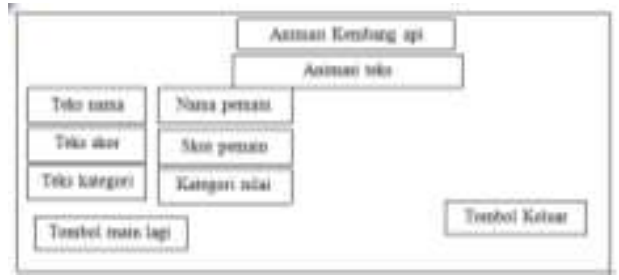

Gambar 5.

Storyboard tampilan kuis tebak nama buah dan sayuran dalam bahasa Inggris 
Pada tampilan storyboard kuis, disini peserta didik bisa memulai menjawab daftar pertanyaan tebak nama buah dan sayuran dalam Bahasa Inggris.

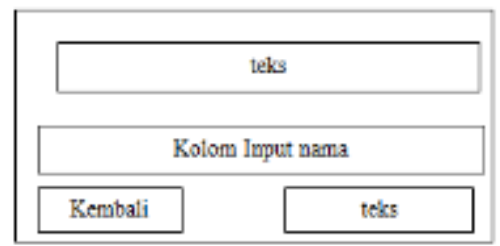

Gambar 6.

Storyboard tampilan hasil kuis tebak nama buah dan sayuran dalam bahasa inggris

Pada gambar 5 memperlihatkan hasil dari kuis yang dikemas dalam permainan digital.

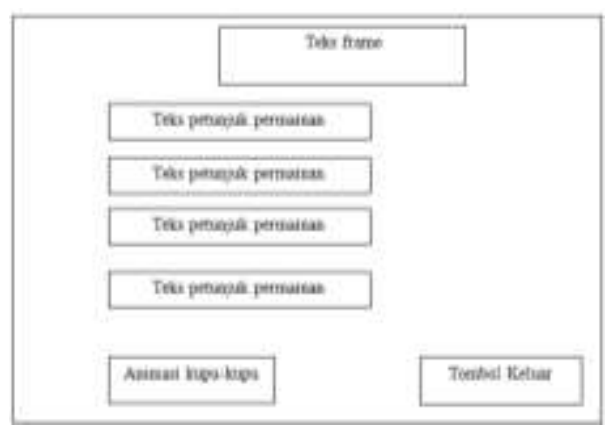

Gambar 7.

Storyboard tampilan petunjuk permainan

Pada game animasi ini juga trerdapat petunjuk permainan agar peserta didik lebih mengerti cara bermain atau mengerjakan kuis tebak buah dan sayuran dalam Bahasa Inggris.

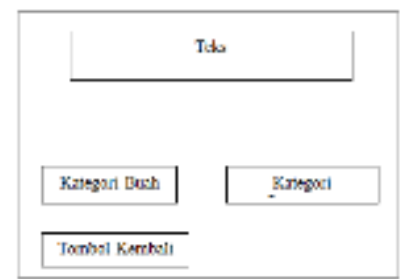

Gambar 8.

Storyboard tampilan kategori belajar

Storyboard category belajar menampilkan dua pilihan yaitu kategori buah dan kategori sayuran serta ada tamabahan tombol kembali ke menu sebelumnya.

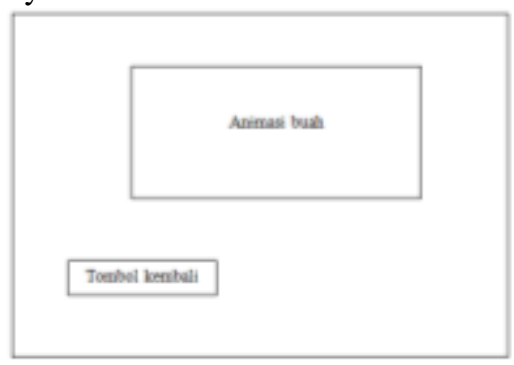

Gambar 9.

Storyboard tampilan kategori belajar buah
Pada gambar 9 menampilkan rancangan storyboard tampilan kategori belajar beberapaq nama buah dalam bahasa Inggris.

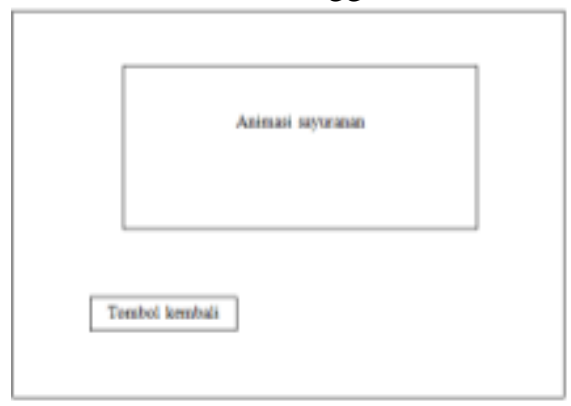

Gambar 10.

Storyboard tampilan kategori belajar sayuran

Pada gambar 10 menggambarkan rancangan tampilan storyboard untuk kategori belajar beberapa nama sayuran dalam bahasa Inggris.

\section{Implementasi dan Pengujian Unit}

\section{Implementasi}

\section{Rancangan antar muka}

a.Tampilan Awal

Tampilan ini berisi judul permainan berserta 4 tombol menu dan 1 tombol navigasi untuk keluar dari permainan.

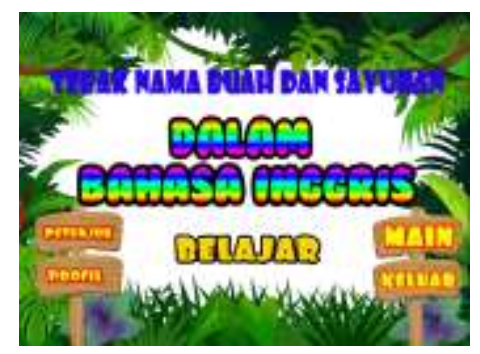

Gambar 11.

Tampilan Menu Utama

Untuk tampilan menu utama dibuat rancangan antar muka yang mudah dipahami oleh peserta didik dengan beberapa tombol pilihan menu.

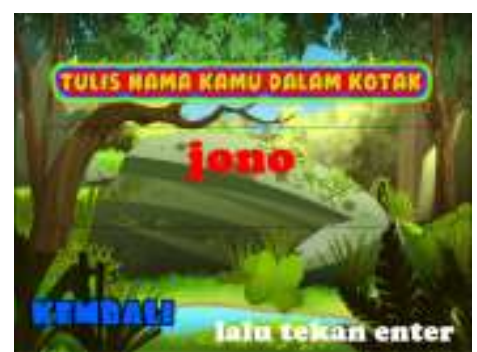

Gambar 12.

Tampilan input nama

Untuk tampilan input nama dibuat sebelum memainkan kuis animasi. 


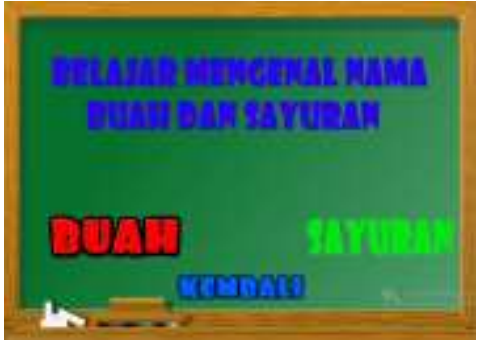

Gambar 13.

Tampilan kategori belajar

Tampilan kategori belajar terdiri dari dua pilihan tombol yaitu buah dan sayuran.

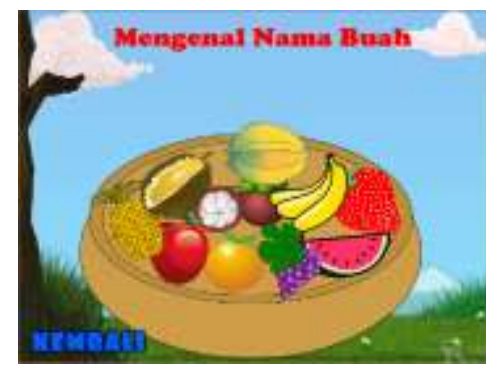

Gambar 14.

Tampilan kategori belajar buah

Setelah user memilih kategori buah selanjutnya masuk ke quis tebak mengenal nama buah dalam bahasa Inggris.

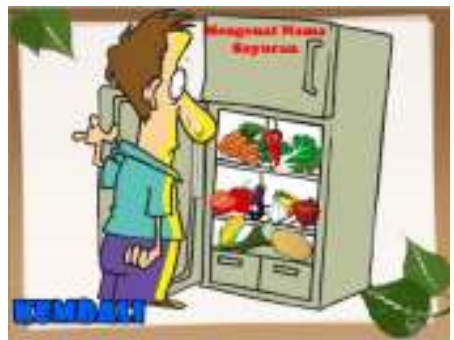

Gambar 15.

Tampilan kategori belajar sayuran

Setelah user memilih kategori sayuran selanjutnya masuk ke quis tebak mengenal nama sayuran dalam bahasa Inggris.

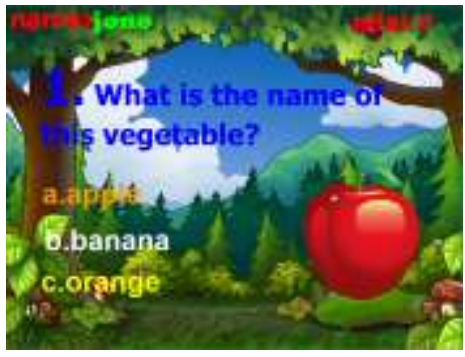

Gambar 16.

Tampilan kuis tebak nama buah dalam bahasa Inggris

Gambar diatas merupakan salah satu tampilan kuis animasi untuk tebak nama buah.

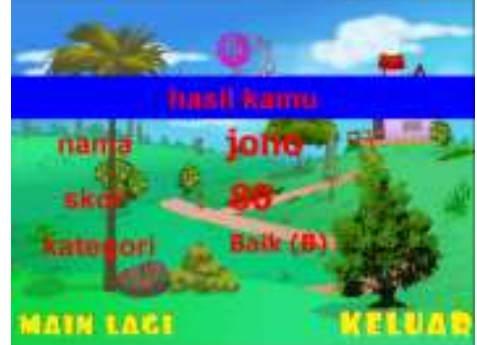

Gambar 17.

Tampilan hasil akhir kuis

Pada tampilan akhir kuis menampilkan nama user yang memainkan beserta skor yang didapat dan kategori berdasarkan skor.

Tabel 1.

Hasil Pengujian Black Box Testing menu utama

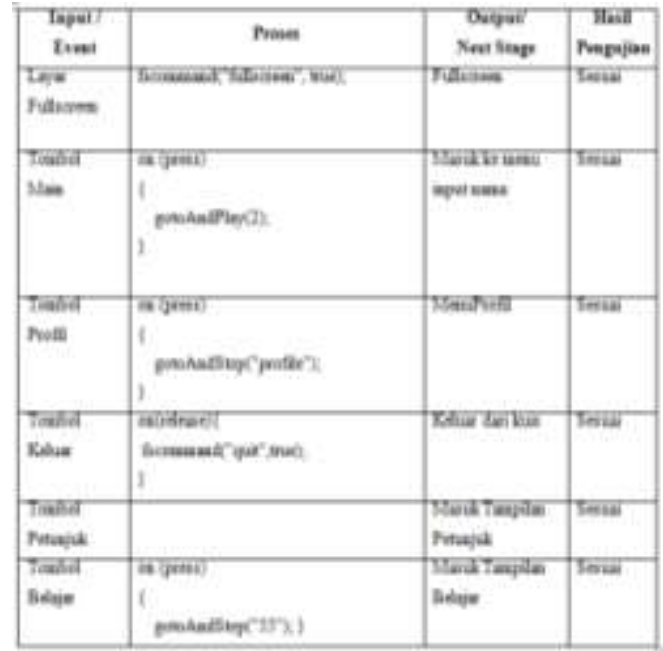

Hasil pengujian blackbox testing pada menu utama sudah di uji untuk tombol-tombol yang terdapat pada game nya, sehingga lebih mudah anakanak dalam menggunakannya.

Tabel 2.

Pengujian kuisioner

\begin{tabular}{|c|c|c|c|}
\hline No & Petanyastit & $\mathrm{r}$ & Dasal \\
\hline 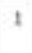 & 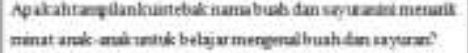 & & \\
\hline 2 & 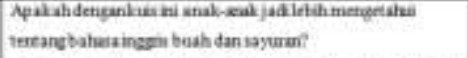 & & \\
\hline 3 & 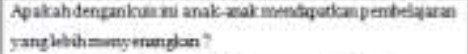 & & \\
\hline 4 & 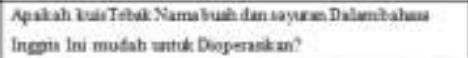 & & \\
\hline 3 & 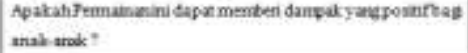 & & \\
\hline 6 & 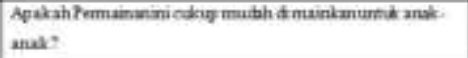 & & \\
\hline T & Aq 2kahsuan y & & \\
\hline $\mathbf{E}$ & 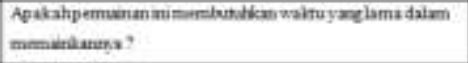 & & \\
\hline
\end{tabular}

Tabel kuesioner diatas peneliti menyesuaikan jenis pertanyaan-pertanyaan dengan game 
pembelajaran yang peneliti buat.

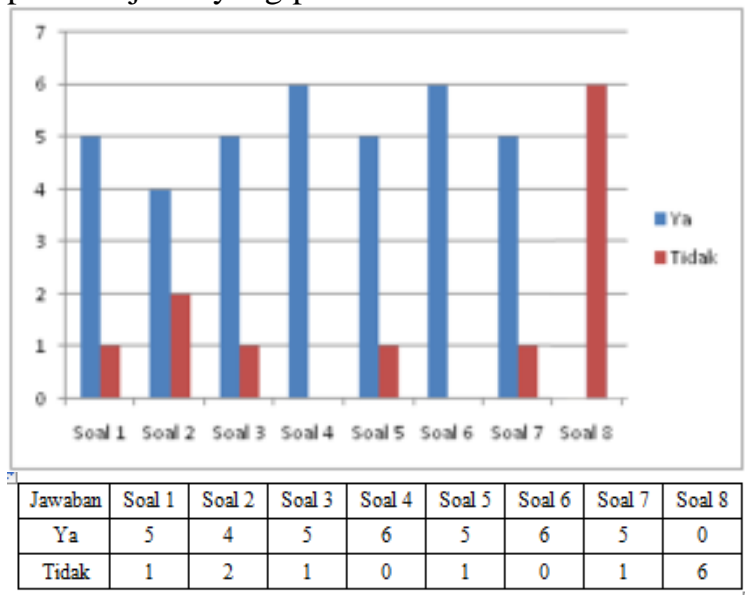

Gambar 18.

Tampilan Grafik Kuisioner

Tampilan dalam tebak buah dan sayuran ini dengan menggunakan sebuah game, anak-anak lebih antusias dan interaktif dalam belajar. Dalam pembelajaran seperti ini anak-anak juga tidak akan lama dalam mengerkajakan tugasnya. Sangat mudah untuk dimainkan anak seusia 6-11 tahun.

\section{KESIMPULAN}

1. Manfaat dari aplikasi yang dibuat oleh penulis dapat memperkenalkan kepada anak-anak tentang nama-nama buah dan sayuran tersebut dalam bahasa inggris.

2. Agar dapat membantu meningkatkan pengetahuan dan pembelajaran siswa-siswi sekolah dasar, mereka juga dapat belajar sambil bermain dengan mudah menggunakan animasi.

\section{REFERENSI}

Elita, V. V. P., \& Asrori, M. A. R. (2019). Pemanfaatan Digital Game Base Learning Dengan Media Aplikasi Kahoot.It Untuk Peningkatan Interaksi Pembelajaran. INSPIRASI: Jurnal Ilmu-Ilmu Sosial, 16(2), 141-150.

https://jurnal.stkippgritulungagung.ac.id/index. php/inspirasi/article/view/1430

Hidayat, R., Psikologi, F., \& Gadjah, U. (2018). Game-Based Learning: Academic Games sebagai Metode Penunjang Pembelajaran Kewirausahaan. 26(2), 71-85. https://doi.org/10.22146/buletinpsikologi.3098 8

Khoerunnisa, F. (2016). Penggunaan Media Digital Game-Based- Learning (Dgbl) Untuk Meningkatkan Hasil Belajar Siswa Pada Pembelajaran Perakitan Komputer Di Smk N 8 Semarang.

Putri, A. R., \& Muzakki, M. A. (2019). Implemetasi Kahoot sebagai Media Pembelajaran Berbasis Digital Game Based Learning dalam Mengahadapi Era Revolusi Industri 4.0. Prosiding Seminar Nasional Universitas Muria Kudus, 1-7. http://pgsd.umk.ac.id/files/prosiding/2019/27_ _Aprilia_Riyana.pdf

Rosmiati, M. (2019). Animasi Interaktif Sebagai Media Pembelajaran Bahasa Inggris Menggunakan Metode ADDIE. Paradigma Jurnal Komputer Dan Informatika, 21(2), 261-268. https://doi.org/10.31294/p.v21i2.6019

Sari, S. A., \& Sakdiah, H. (2016). The Development of Mind Mapping Media in Flood Material using ADDIE Model. Journal of Education and Learning (EduLearn), 10(1), 53. https://doi.org/10.11591/edulearn.v10i1.3227 